die Bedeutung des Versöhnungstages als auch für Personen geltend, wie oben ausgeführt, im Buche Lev. eben eine erweiterte, über die ursprüngliche weit hinausgehende ist.

New-York, December 1882.

\title{
Salomos Alter bei der Thronbesteigung.
}

Aus einem Briefe von Dr. David Kanfmann in Budapest an den Herausgeber.

(S. Jahrgang 1882, S. 312 ff.)

II, 314 Threr Ztsch. wird die Quelle gesucht für die Ueberlieferung, Salomo sei bei seinem Regierungsantritt zwölf Jahre alt gewesen. Diese Angabe und ihre Begründung findet sich zuerst in Seder Olam r. c. 74 (vgl. Zunz, Gottesdienstliche Vorträge S. 85). Von hier hat Raschi sie übernommen und darum führt David Kimchi in seinem Commentar zu 1 Reg. 3, 7 sie als rabbinische Tradition unter der Formel bi 7 an. Eine vortreffliche Auseinandersetzung der gegen diese Annahme sich erhebenden Einwendungen hat Isak A bravanel in seinem Commentar z. St. gegeben, wo er zu dem Ergebnifs gelangt, dafs 20 Jahre wohl das Alter Salomos, zur Zeit seines Regierungsantritts gewesen sein dürfte.

Die Angabe von 12 Jahren ist auch in die jüdischen Chronographen, ich nenne z. B. Gedalja Ibn Jachja, übergegangen.

In der deutschen Uebersetzung dieser dem Seder Olam entnommenen Berechnung ist der Schlufs S. 314 Z. 8 ein Mifsverständnifs und zu berichtigen.

Budapest, 8. Sept. 1882. 